\title{
Role of enhanced vector transmission of a new West Nile virus strain in an outbreak of equine disease in Australia in 2011
}

Andrew F van den Hurk ${ }^{1,2^{*}}$, Sonja Hall-Mendelin ${ }^{1}$, Cameron E Webb ${ }^{3}$, Cindy S E Tan ${ }^{2}$, Francesca D Frentiu ${ }^{4}$, Natalie A Prow ${ }^{2}$ and Roy A Hall ${ }^{2}$

\begin{abstract}
Background: In 2011, a variant of West Nile virus Kunjin strain $\left(W_{N V} V_{\text {KUN }}\right)$ caused an unprecedented epidemic of neurological disease in horses in southeast Australia, resulting in almost 1,000 cases and a 9\% fatality rate. We investigated whether increased fitness of the virus in the primary vector, Culex annulirostris, and another potential vector, Culex australicus, contributed to the widespread nature of the outbreak.
\end{abstract}

Methods: Mosquitoes were exposed to infectious blood meals containing either the virus strain responsible for the

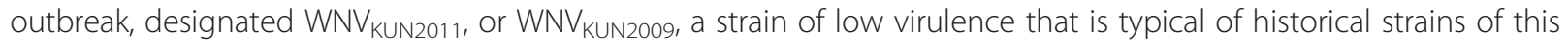
virus. $W N V_{\text {KUN }}$ infection in mosquito samples was detected using a fixed cell culture enzyme immunoassay and a $W N V_{K_{U N}}$ specific monoclonal antibody. Probit analysis was used to determine mosquito susceptibility to infection. Infection, dissemination and transmission rates for selected days post-exposure were compared using Fisher s exact test. Virus titers in bodies and saliva expectorates were compared using $t$-tests.

Results: There were few significant differences between the two virus strains in the susceptibility of $C_{X}$. annulirostris to infection, the kinetics of virus replication and the ability of this mosquito species to transmit either strain. Both strains were transmitted by $C_{X}$. annulirostris for the first time on day 5 post-exposure. The highest transmission rates

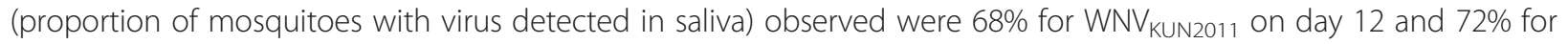

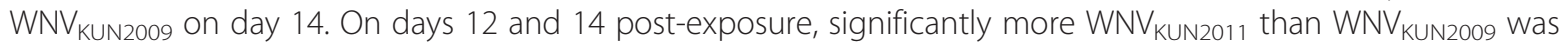
expectorated by infected mosquitoes. Infection, dissemination and transmission rates of the two strains were not significantly different in Culex australicus. However, transmission rates and the amount of virus expectorated were significantly lower in Cx. australicus than CX. annulirostris.

Conclusions: The higher amount of WNV $\mathrm{KUN}_{2011}$ expectorated by infected mosquitoes may be an indication that this virus strain is transmitted more efficiently by $C X$. annulirostris compared to other $W_{N V_{K U N}}$ strains. Combined with other factors, such as a convergence of abundant mosquito and wading bird populations, and mammalian and avian feeding behaviour by $C$. annulirostris, this may have contributed to the scale of the 2011 equine epidemic.

Keywords: Arbovirus, West Nile virus Kunjin strain, Culex annulirostris, Infection, Transmission, Australia

\footnotetext{
* Correspondence: andrew.vandenhurk@health.qld.gov.au

'Virology, Public and Environmental Health, Forensic and Scientific Services,

Department of Health, Queensland Government, Brisbane, QLD, Australia

${ }^{2}$ Australian Infectious Disease Research Centre, School of Chemistry and

Molecular Biosciences, University of Queensland, Brisbane, QLD, Australia

Full list of author information is available at the end of the article
} 


\section{Background}

West Nile virus (WNV) is a mosquito-borne flavivirus that historically was responsible for outbreaks of acute encephalitis in Africa, Europe, Russia and the Middle East [1], but is most notable for its emergence in the Americas [2]. The Kunjin strain of WNV $\left(\mathrm{WNV}_{\text {KUN }}\right)$ is endemic in Australia, where it can cause a mild febrile illness and occasionally non-fatal encephalitis in humans and horses [3]. The virus is endemic in northern Australia and occasionally spreads into southern regions when heavy rainfall and flooding create an ideal environment for ardeid birds, the key amplifying hosts, and the proliferation of Culex annulirostris, the primary mosquito vector [4].

Between January and June 2011, a widespread outbreak of neurological disease attributed to arbovirus infection occurred amongst horses in southeastern Australia resulting in 982 reported equine cases, with an overall case fatality rate of 9\% [5]. In addition to Ross River virus and Murray Valley encephalitis virus (MVEV), a WNVlike virus was isolated from mosquitoes and deceased horses, and was revealed antigenically and genotypically to be a strain of $\mathrm{WNV}_{\mathrm{KUN}}$ [6]. This strain of $\mathrm{WNV}_{\mathrm{KUN}}$, designated $\mathrm{WNV}_{\mathrm{KUN2011}}$, was subsequently shown to be the primary cause of neurological disease in horses $[5,6]$. This was unexpected, because unlike the North American strain of WNV, which is highly pathogenic to horses, $\mathrm{WNV}_{\mathrm{KUN}}$ is only rarely associated with equine disease [3,7]. Paradoxically, there were very few human clinical cases attributed to infection with $\mathrm{WNV}_{\mathrm{KUN}}$ from epidemic foci during 2011 [6]. Furthermore, a crosssectional serosurvey of 1,115 human serum specimens from a focus of $\mathrm{WNV}_{\mathrm{KUN}}$ in Victoria found less than $0.3 \%$ were IgM positive, providing little evidence of recent exposure amongst the human population [8]. In contrast to North American WNV, which is highly pathogenic in a number of bird species $[9,10]$, there was no increased mortality observed in birds during the 2011 outbreak [6].

Of note, other key epidemiological and biological features characterized this unique outbreak. La Nia-driven widespread rainfall and extensive flooding in southeastern Australia during the spring and summer of 20102011 [11] triggered an explosion of mosquito numbers, particularly in inland areas. Indeed, over 200,000 mosquitoes were collected during the 20102011 season in New South Wales, which was considerably higher than numbers collected in the preceding two years [12]. $\mathrm{WNV}_{\mathrm{KUN}}$ was also reported in novel areas, such as east of the Great Dividing Range near the major coastal population centers of Sydney, Newcastle and Wollongong [5,6]. This included the first virus isolate from mosquitoes collected from the eastern seaboard [12].

A key factor that may have led to the 2011 outbreak was increased fitness of $\mathrm{WNV}_{\mathrm{KUN} 2011}$ in mosquitoes, similar to what has been suggested for emergent strains of WNV in North America [13,14]. To examine the mechanisms of its emergence, we report the characterization of the $\mathrm{WNV}_{\mathrm{KUN} 2011}$ strain in $C x$. annulirostris and compare it to a recent strain of $\mathrm{WNV}_{\mathrm{KUN}}$ that has not been associated with recognized pathogenicity in horses or other vertebrates. Infection characteristics of the two virus strains were also evaluated in another potential vector, Culex australicus. This species is an indigenous member of the Culex pipiens group, a complex which contains major WNV vectors in North America and Europe [15,16]. It has a wide distribution across southern Australia, south of 17S [17], including the region affected by the epidemic.

\section{Methods}

\section{Virus strains}

The $\mathrm{WNV}_{\mathrm{KUN2011}}$ was isolated from the brain of a deceased horse from Boorowa (3428 'S; 14845 'N), NSW. It had been passaged three times, once each in baby hamster kidney (BHK), African green monkey (Vero) and Aedes albopictus (C6/36) cells and the stock virus had a final titre of $10^{8.9}$ tissue culture infectious dose (TCID) $)_{50} / \mathrm{mL}$. The strain to which it was compared $\left(\mathrm{WNV}_{\mathrm{KUN2009}}\right)$ was isolated from $C x$. annulirostris collected from Kununurra (1546 'S; 12844 'N), Western Australia, in 2009. It had been passaged twice in C6/36 cells, once in porcine stable equine kidney (PSEK) cells before a final passage in C6/36 cells; the stock virus had a final titre of $10^{8.7} \mathrm{TCID}_{50} / \mathrm{mL}$.

\section{Mosquitoes}

Adult $C x$. annulirostris and $C x$. australicus were collected from a number of sites around Hexham Swamp (3250 'S; 15140 'E), Fullerton Cove (3250 'S; 15150 'E) and Kooragang Island (3252 'S;15145 'E) near Newcastle, NSW, using encephalitis virus surveillance (EVS) light traps [18] baited with $\mathrm{CO}_{2}$ (approx. $1 \mathrm{~kg}$ dry ice). The mosquitoes were transported to the laboratory and placed in a $30 \quad 30 \quad 30 \mathrm{~cm}$ cage at $26 \mathrm{C}, 75 \%$ humidity and 12:12 L:D. On the night following collection, mosquitoes were offered an anesthetized rat as a blood meal source. The use of animals was approved by the University of Sydney and Westmead Hospital Animal Ethics Committee (approval number 8001/04-10). Two days later, $200 \mathrm{~mL}$ of water was added to the cage for oviposition. After two days, egg rafts were removed, placed on moist filter paper in a Petri dish and forwarded by overnight courier to Forensic and Scientific Services, Department of Health, Brisbane.

Upon receipt, eggs were hatched in $2.5 \mathrm{~L}$ of $\mathrm{ddH}_{2} \mathrm{O}$ containing $\sim 45 \mathrm{mg}$ of brain-heart infusion powder. First and 2nd instar larvae were fed a 1:1 mixture of brewer s yeast (Brewer s Yeast, Healthy Life) and fish flakes (Wardleys Tropical Fish Food Flakes, The Hartz 
Mountain Corporation, NJ), while 3rd and 4th instar larvae were fed on Hikari Cichlid Staple pellets (Kyorin co. Ltd, Himeji, Japan). Pupae were placed in $150 \mathrm{~mL}$ containers within a $3030 \quad 30 \mathrm{~cm}$ cage and emerged adults were provided $15 \%$ honey water ad libitum. Prior to virus exposure, mosquitoes were sorted by species and 57 day old females placed into $900 \mathrm{~mL}$ gauze-covered containers.

\section{Virus exposure}

Mosquitoes were exposed for 2 hours to hanging drops of a blood/virus suspension containing stock virus, commercially available defibrinated sheep blood (Applied Biological Products Management Australia, Aldinga Beach, Australia) and 1\% sucrose [19]. For testing susceptibility to infection, $C x$. annulirostris were offered blood meals containing 10 -fold dilutions of stock virus, whilst $C x$. australicus was exposed to a single dose of virus only. To determine the titer of virus at the time of feeding, $100 \mu \mathrm{L}$ samples of the pre- and post-feeding blood/virus suspensions were diluted in $900 \mu \mathrm{L}$ of growth media with antibiotics and antimycotics (GM; Gibco BRL, Invitrogen, California) and supplemented with $3 \%$ fetal bovine serum (FBS), before being stored at $-80 \mathrm{C}$.

Following feeding, mosquitoes were sorted and blood engorged mosquitoes placed in $900 \mathrm{~mL}$ gauze-covered containers. Containers were placed in sealed rigid plastic boxes within an environmental growth cabinet at $28 \mathrm{C}$ and 12:12 L:D. Relative humidity was increased by placing a moist cotton wool pad within the plastic boxes and $10 \%$ sucrose was provided as a carbohydrate source.

\section{Measurement of susceptibility to infection, and virus dissemination and transmission}

For the susceptibility trials, at day 14 post exposure, $C x$. annulirostris fed the three lowest virus titers were killed via exposure to $\mathrm{CO}_{2}$ and placed individually in $2 \mathrm{~mL}$ vials containing $1 \mathrm{~mL}$ of $\mathrm{GM}+3 \%$ FBS and a $5 \mathrm{~mm}$ stainless steel ball. To compare virus replication and the length of the incubation period for the two viruses in Cx. annulirostris, on days 3, 5, 7, 10, 12 and 14, mosquitoes fed the highest virus titer were tested for their ability to transmit virus using the forced salivation method of Aitken [20]. Due to low survival rates following virus exposure, $C x$. australicus were only tested for their ability to transmit at day 12 . For transmission attempts, mosquitoes were anaesthetized with $\mathrm{CO}_{2}$ gas, their legs and wings removed and the proboscis of each mosquito inserted into a microcapillary tube containing $25 \mu \mathrm{L}$ of GM $+20 \%$ FBS. After approx. 30 min the contents of the tube were expelled into a $2 \mathrm{~mL}$ vial containing $500 \mu \mathrm{L}$ of GM $+3 \%$ FBS. The body remnants, and legs and wings were placed separately in $2 \mathrm{~mL}$ vials containing $1 \mathrm{~mL}$ of $\mathrm{GM}+3 \%$ FBS and a $5 \mathrm{~mm}$ stainless steel ball. Recovery of virus from the legs and wings is indicative of a disseminated infection, whereby the virus has escaped from the midgut and disseminated through the hemocoel [21]. The whole bodies, body remnants, and legs and wings, were homogenized in a QIAGEN TissueLyser II (Qiagen, Hilden, Germany) before being stored, along with the saliva expectorates, at $-80 \mathrm{C}$.

\section{Virus detection}

The pre- and post-exposure blood/virus suspensions were inoculated as 10-fold dilutions in the wells of a 96-well microtiter plate containing confluent layers of C6/36 cells. Plates were incubated at $28 \mathrm{C}$ for seven days, after which time they were fixed with PBS/20\% acetone with $0.2 \% \mathrm{BSA}$ and stored at $-20 \mathrm{C}$.

Mosquito homogenates were filtered through a $0.2 \mu \mathrm{m}$ Supor membrane filter (Pall Corporation, Ann Arbor, MI). The body filtrate of the mosquitoes exposed to the three lowest virus titers, and the legs and wings filtrate, were inoculated in duplicate onto $\mathrm{C6/36}$ cell monolayers within a 96-well microtitre plate. The filtrate of the remaining bodies and all saliva expectorates were inoculated as 10-fold dilutions in the wells of a 96-well microtiter plate containing confluent monolayers of C6/36 cells. Plates were incubated, fixed and stored as described above.

A fixed cell culture enzyme immunoassay (CCEIA) was used to detect $\mathrm{WNV}_{\mathrm{KUN}}$ infection in all blood/virus mixtures and mosquito samples using the $\mathrm{WNV}_{\mathrm{KUN}^{-}}$ specific monoclonal antibody, 10A1 [22].

\section{Analysis}

The titer of the blood/virus suspension, and the mosquito bodies and saliva expectorates was calculated using the method of Reed and Meunch [23] and expressed as $\mathrm{TCID}_{50} / \mathrm{mL}$. The susceptibility of $C x$. annulirostris to infection with the two $\mathrm{WNV}_{\mathrm{KUN}}$ strains was calculated by probit analysis using PriProbit version 1.63 (Kyoto University, Kyoto, Japan). Log-log models were assessed using the Pearson chi-square goodness-of-fit statistic and susceptibility to infection was expressed as ID $_{50} 95 \%$ confidence intervals (CIs) and defined as the virus dose per $\mathrm{mL}$ at which $50 \%$ of $C x$. annulirostris tested positive for $\mathrm{WNV}_{\mathrm{KUN}}$ infection in the CCEIA. Overlap of $95 \%$ CIs was used as a test of statistical significance.

Infection, dissemination and transmission rates in $C x$. annulirostris and $C x$. australicus exposed to $\mathrm{WNV}_{\mathrm{KUN} 2011}$ and $\mathrm{WNV}_{\mathrm{KUN2009}}$ were compared using Fisher s exact test [24]. Differences in virus titer within bodies and saliva expectorates from $C x$. annulirostris and $C x$. australicus exposed to $\mathrm{WNV}_{\mathrm{KUN} 2011}$ and $\mathrm{WNV}_{\mathrm{KUN} 2009}$ were analyzed for each day of exposure using $t$-tests [24]. 


\section{Results}

Culex annulirostris susceptibility to infection with WNV KUN $_{\text {N }}$ Mosquitoes were exposed to doses of $\mathrm{WNV}_{\mathrm{KUN2011}}$ ranging from $10^{4.4}$ to $10^{8.1} \mathrm{TCID}_{50} / \mathrm{mL}$, and $10^{4.8}$ to $10^{7.6}$ $\mathrm{TCID}_{50} / \mathrm{mL}$ for $\mathrm{WNV}_{\text {KUN2009 }}$ (Figure 1). The susceptibilities of $C x$. annulirostris to infection with the $\mathrm{WNV}_{\mathrm{KUN} 2011}$ and $\mathrm{WNV}_{\mathrm{KUN} 2009}$, expressed as $\mathrm{ID}_{50}$, were $10^{7.9}\left(10^{7.4}\right.$ $\left.10^{8.7}, 95 \% \mathrm{CI}\right) \mathrm{TCID}_{50}$ per $\mathrm{mL}\left(\mathrm{X}^{2}=2.26, \mathrm{df}=2, P=0.332\right)$ and $10^{7.1}\left(10^{6.9}-10^{7.4}, 95 \% \mathrm{CI}\right) \mathrm{TCID}_{50}$ per $\mathrm{mL}\left(\chi^{2}=5.58\right.$, $\mathrm{df}=2=, \mathrm{P}=0.06$ ), respectively. Although there was no statistically significant difference in susceptibility to the virus strains, the overlap between CIs was very small.

\section{Infection and dissemination in and transmission by $C x$. annulirostris}

Culex annulirostris were exposed to virus titers of $10^{8.1}$ and $10^{7.6} \mathrm{TCID}_{50} / \mathrm{mL}$ of $\mathrm{WNV}_{\mathrm{KUN} 2011}$ and $\mathrm{WNV}_{\mathrm{KUN} 2009}$, respectively. There was no significant difference $(P>0.05)$ in infection rates in $C x$. annulirostris exposed to the two $\mathrm{WNV}_{\mathrm{KUN}}$ strains on any day post exposure, except at day 14 , where significantly more mosquitoes were infected with $\mathrm{WNV}_{\mathrm{KUN} 2009}$ compared to $\mathrm{WNV}_{\mathrm{KUN} 2011}(P=0.0322$; Table 1$)$. There was no significant difference $(P>0.05)$ in the overall dissemination rate or the rate of dissemination in infected mosquitoes between $C x$. annulirostris exposed to the two $\mathrm{WNV}_{\mathrm{KUN}}$ strains on any day post-exposure (Table 1). Transmission for both virus strains was first observed at day 5 post-exposure, where 3/25 mosquitoes expectorated the virus (Table 1 ). There was no significant difference $(P>0.05)$ in the overall transmission rate or the transmission rate in mosquitoes with a disseminated infection on any day post-exposure.
With the exception of day 14, body titers in $C x$. annulirostris infected with $\mathrm{WNV}_{\mathrm{KUN} 2011}$ were higher than those infected with $\mathrm{WNV}_{\mathrm{KUN2009}}$ (Figure 2A) and significantly higher on days 7 and $10(P<0.001)$. Conversely, on day 14, $\mathrm{WNV}_{\mathrm{KUN} 2009}$-infected mosquitoes had significantly higher body titers than $\mathrm{WNV}_{\mathrm{KUN} 2011}$-infected mosquitoes $(P<0.001)$, which coincided with the significantly higher infection rate observed above. On days 10 14, when a greater proportion of mosquitoes was transmitting the virus, there was a higher amount of virus expectorated by $\mathrm{WNV}_{\mathrm{KUN} 2011}$-infected mosquitoes, with significant differences observed on days 12 and $14(P<0.05$; Figure $2 B)$.

\section{Infection and dissemination in and transmission by Cx. australicus}

There was no significant difference $(P>0.05)$ in infection, dissemination and transmission rates in $C x$. australicus 12 days after being exposed to virus titers of $10^{8.1}$ and $10^{7.6} \mathrm{TCID}_{50} / \mathrm{mL}$ of $\mathrm{WNV}_{\mathrm{KUN} 2011}$ and $\mathrm{WNV}_{\mathrm{KUN} 2009}$, respectively (Table 2). The infection and dissemination rates were also not significantly different $(P>0.05)$ from those observed for $C x$. annulirostris. However, the overall transmission rate was significantly lower $(P<0.05)$ in $C x$. australicus than $C x$. annulirostris for both $\mathrm{WNV}_{\mathrm{KUN} 2011}$ and $\mathrm{WNV}_{\mathrm{KUN2009}}$ (Table 2). Similarly, the transmission rate in mosquitoes with a disseminated infection was lower in $C x$. australicus than $C x$. annulirostris, with the difference being significant $(P<0.05)$ for $\mathrm{WNV}_{\mathrm{KUN} 2011}$.

The body titers in $C x$. australicus exposed to $\mathrm{WNV}_{\mathrm{KUN} 2011}$ were significantly lower $(P<0.05)$ than those exposed to $\mathrm{WNV}_{2009}$ (Figure 3A). They were also significantly lower $(P<0.001)$ than the body titers observed for both viruses in $C x$. annulirostris. There was no significant

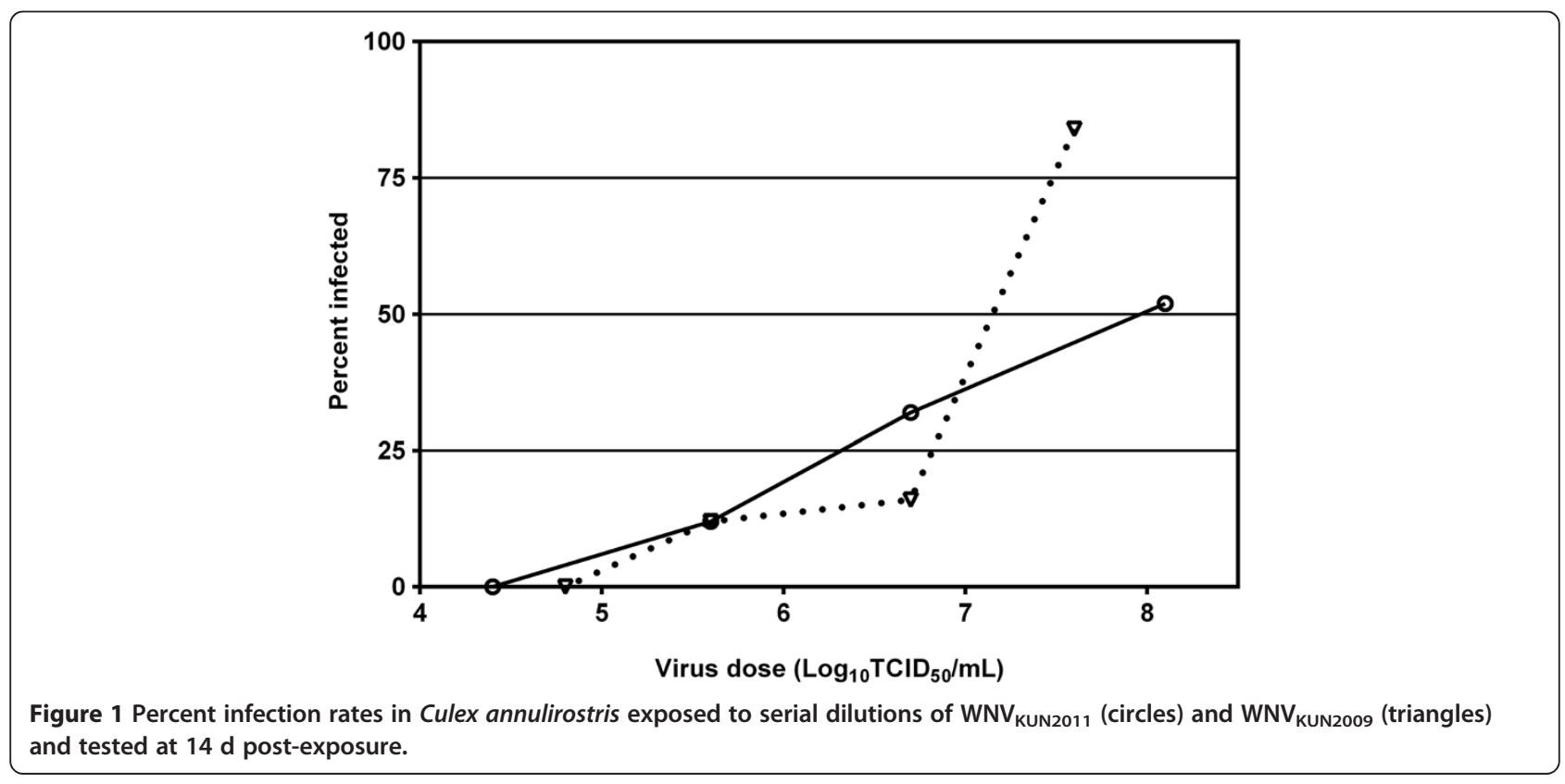




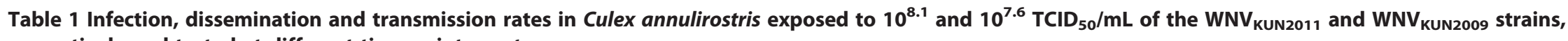
respectively and tested at different time points post-exposure

\begin{tabular}{|c|c|c|c|c|c|c|c|c|c|c|c|c|c|c|c|c|c|c|c|c|}
\hline \multirow{3}{*}{$\frac{\text { Day post exposure }}{3}$} & \multicolumn{4}{|c|}{ Infection $^{a}$} & \multicolumn{4}{|c|}{ Dissemination $^{\mathbf{b}}$} & \multicolumn{4}{|c|}{ Dissemination/infection $^{c}$} & \multicolumn{4}{|c|}{ Transmission $^{d}$} & \multicolumn{4}{|c|}{ Transmission/dissemination $^{\mathrm{e}}$} \\
\hline & \multicolumn{2}{|c|}{ KUN2011 } & \multicolumn{2}{|c|}{ KUN2009 } & \multicolumn{2}{|c|}{ KUN2011 } & \multicolumn{2}{|c|}{ KUN2009 } & \multicolumn{2}{|c|}{ KUN2011 } & \multicolumn{2}{|c|}{ KUN2009 } & \multicolumn{2}{|c|}{ KUN2011 } & \multicolumn{2}{|c|}{ KUN2009 } & \multicolumn{2}{|c|}{ KUN2011 } & \multicolumn{2}{|c|}{ KUN2009 } \\
\hline & 76 & $(19 / 25)$ & 64 & $(16 / 25)$ & 28 & $(7 / 25)$ & 32 & $(8 / 25)$ & 37 & $(7 / 19)$ & 50 & $(8 / 16)$ & 0 & $(0 / 25)$ & 0 & $(0 / 25)$ & 0 & $(0 / 7)$ & 0 & $(0 / 8)$ \\
\hline 5 & 68 & $(17 / 25)$ & 68 & $(17 / 25)$ & 60 & $(15 / 25)$ & 64 & $(16 / 25)$ & 88 & $(15 / 17)$ & 94 & $(16 / 17)$ & 12 & $(3 / 25)$ & 12 & $(3 / 25)$ & 20 & $(3 / 15)$ & 19 & $(3 / 16)$ \\
\hline 7 & 64 & $(16 / 25)$ & 68 & $(17 / 25)$ & 64 & $(16 / 25)$ & 52 & $(13 / 25)$ & 100 & $(16 / 16)$ & 76 & $(13 / 17)$ & 28 & $(7 / 25)$ & 12 & $(3 / 25)$ & 44 & $(7 / 16)$ & 23 & (3/13) \\
\hline 10 & 64 & $(16 / 25)$ & 44 & $(11 / 25)$ & 64 & $(16 / 25)$ & 44 & $(11 / 25)$ & 100 & $(16 / 16)$ & 100 & $(11 / 11)$ & 44 & $(11 / 25)$ & 40 & $(10 / 25)$ & 69 & $(11 / 16)$ & 91 & $(10 / 11)$ \\
\hline 12 & 68 & $(17 / 25)$ & 60 & $(9 / 15)$ & 68 & $(17 / 25)$ & 60 & $(9 / 15)$ & 100 & $(17 / 17)$ & 100 & $(9 / 9)$ & 68 & $(17 / 25)$ & 53 & (8/15) & 100 & $(17 / 17)$ & 89 & (8/9) \\
\hline 14 & 52 & $(13 / 25)$ & 84 & $(21 / 25)^{*}$ & 52 & $(13 / 25)$ & 76 & $(19 / 25)$ & 100 & $(13 / 13)$ & 90 & $(19 / 21)$ & 52 & $(13 / 25)$ & 72 & $(18 / 25)$ & 100 & $(13 / 13)$ & 95 & $(18 / 19)$ \\
\hline
\end{tabular}

apercentage of mosquitoes containing virus in their bodies (number positive/number tested).

${ }^{\mathrm{b} P e r c e n t a g e}$ of mosquitoes containing virus in their legs and wings (number positive/number tested).

'Percentage of infected mosquitoes containing virus in their legs and wings (number positive/number infected).

dPercentage of mosquitoes containing virus in the saliva expectorates (number positive/number tested).

e Percentage of mosquitoes with a disseminated infection containing virus in the saliva expectorates (number positive/number dissemint).

*Fishers exact test $P$-value $<0.05$ for day 14 infection rate. 

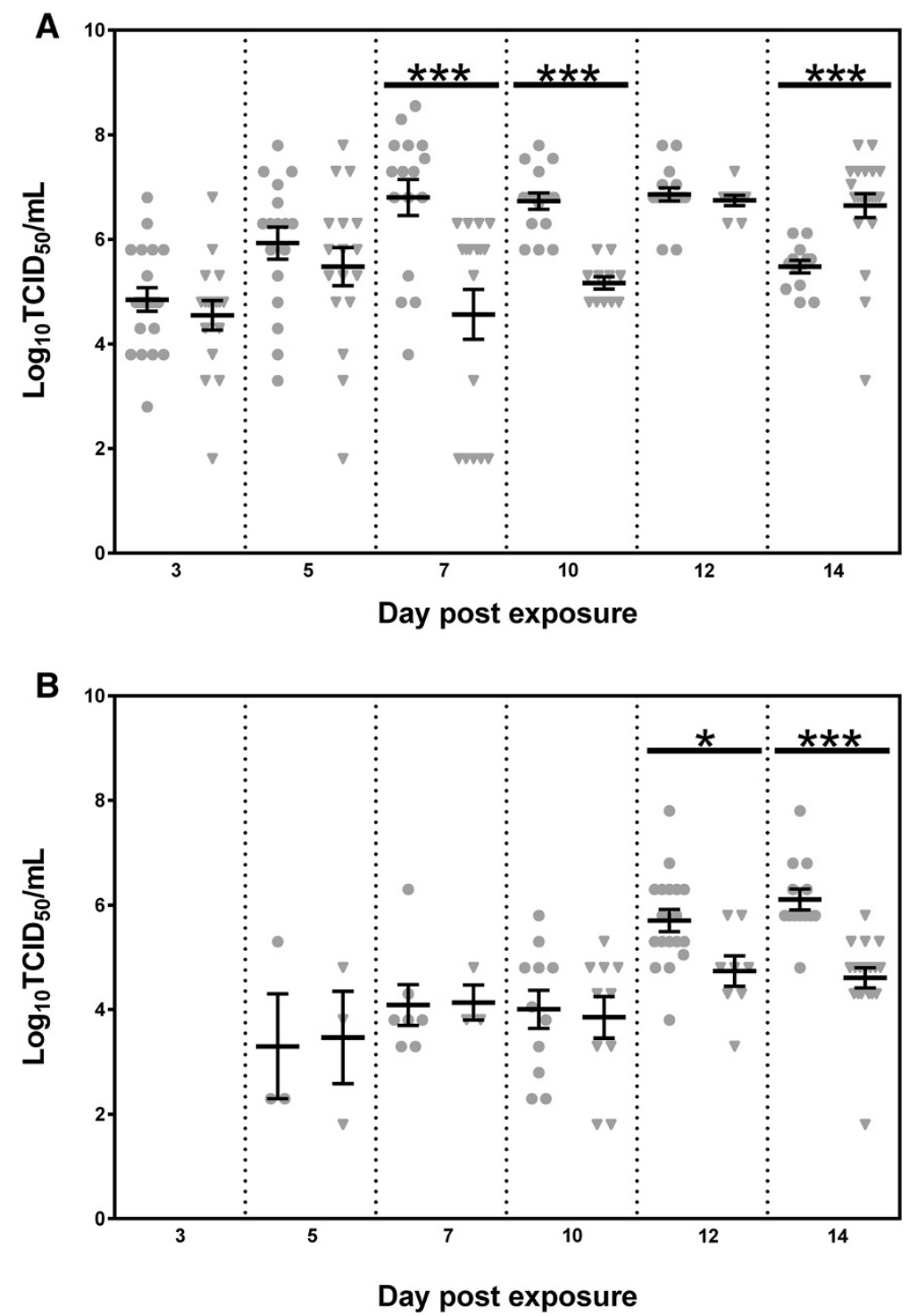

Figure 2 Replication of $\mathrm{WNV}_{\mathrm{KUN2011}}$ and $\mathrm{WNV}_{\mathrm{KUN2009}}$ in the bodies (A) of Culex annulirostris and amount of virus expectorated in the saliva (B) by infected $C x$. annulirostris, following the ingestion of an infectious blood meal. Each point (circles for $W_{N V} V_{K U N 2011}$ and triangles

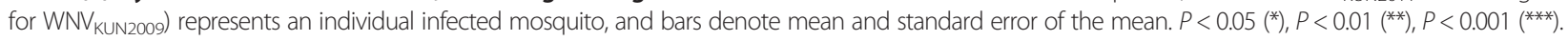

Table 2 Infection, dissemination and transmission rates in Culex australicus and Culex annulirostris exposed to $10^{8.1}$ and $10^{7.6} \mathrm{TCID}_{50} / \mathrm{mL}$ of the $\mathrm{WNV}_{\mathrm{KUN2011}}$ and $\mathrm{WNV}_{\mathrm{KUN2009}}$ strains, respectively, and tested at day 12 post-exposure

\begin{tabular}{|c|c|c|c|c|c|c|c|c|c|c|c|c|c|c|c|c|c|c|c|c|}
\hline \multirow{3}{*}{$\frac{\text { Species }}{\text { CX. australicus }}$} & \multicolumn{4}{|c|}{ Infection $^{a}$} & \multicolumn{4}{|c|}{ Dissemination $^{b}$} & \multicolumn{4}{|c|}{$\begin{array}{l}\text { Dissemination/ } \\
\text { infection }^{c}\end{array}$} & \multicolumn{4}{|c|}{ Transmission $^{d}$} & \multicolumn{4}{|c|}{$\begin{array}{l}\text { Transmission/ } \\
\text { dissemination }\end{array}$} \\
\hline & \multicolumn{2}{|c|}{ KUN2011 } & \multicolumn{2}{|c|}{ KUN2009 } & \multicolumn{2}{|c|}{ KUN2011 } & \multicolumn{2}{|c|}{ KUN2009 } & \multicolumn{2}{|c|}{ KUN2011 } & \multicolumn{2}{|c|}{ KUN2009 } & \multicolumn{2}{|c|}{ KUN2011 } & \multicolumn{2}{|c|}{ KUN2009 } & \multicolumn{2}{|c|}{ KUN2011 } & \multicolumn{2}{|c|}{ KUN2009 } \\
\hline & 68 & $(17 / 25)$ & 50 & $(11 / 22)$ & 60 & $(15 / 25)$ & 41 & $(9 / 22)$ & 88 & $(15 / 17)$ & 82 & $(9 / 11)$ & 20 & $(5 / 25)^{*}$ & 18 & $(4 / 22)^{*}$ & 33 & $(5 / 15)^{*}$ & 44 & $(4 / 9)$ \\
\hline Cx. annulirostris & 68 & $(17 / 25)$ & 60 & $(9 / 15)$ & 68 & $(17 / 25)$ & 60 & $(9 / 15)$ & 100 & $(17 / 17)$ & 100 & $(9 / 9)$ & 68 & $(17 / 25)$ & 53 & $(8 / 15)$ & 100 & $(17 / 17)$ & 89 & $(8 / 9)$ \\
\hline
\end{tabular}

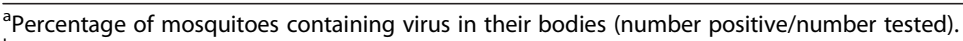

${ }^{b}$ Percentage of mosquitoes containing virus in their legs and wings (number positive/number tested).

${ }^{c}$ Percentage of infected mosquitoes containing virus in their legs and wings (number positive/number infected).

dPercentage of mosquitoes containing virus in the saliva expectorates (number positive/number tested).

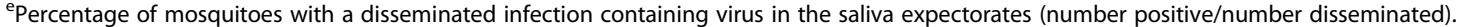

*Fisher s exact test $P$-value $<0.05$ for comparisons between $C x$. australicus and $C x$. annulirostris. 

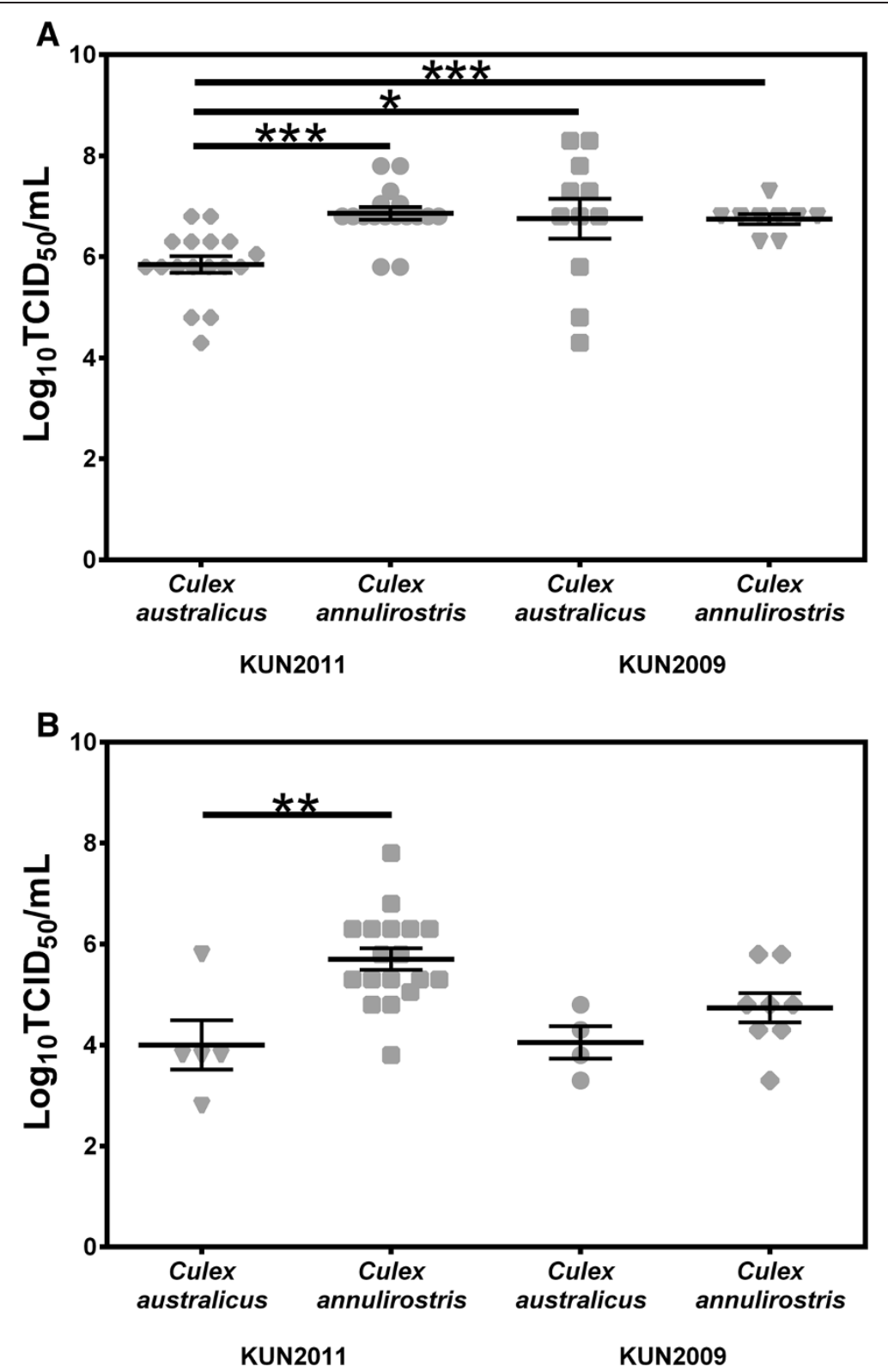

Figure 3 Replication of $\mathrm{WNV}_{\mathrm{KUN} 2011}$ and $\mathrm{WNV}_{\mathrm{KUN} 2009}$ in the bodies (A) of Culex australicus and Culex annulirostris and amount of virus expectorated in the saliva (B) by infected $C_{x}$. australicus and $C_{X}$. annulirostris, 12 days after ingesting an infectious blood meal. Each point on the plot represents an individual infected mosquito, and bars denote mean and standard error of the mean. $P<0.05\left({ }^{*}\right), P<0.01(* *)$, $P<0.0011^{(* *)}$.

difference $(P>0.05)$ between the amount of $\mathrm{WNV}_{\mathrm{KUN} 2011}$ or $\mathrm{WNV}_{\mathrm{KUN2009}}$ expectorated by $C x$. australicus (Figure 3B). However, lower amounts of each virus strain were expectorated by $C x$. australicus when compared to $C x$. annulirostris, with this difference significant $(P<0.05)$ for $\mathrm{WNV}_{\mathrm{KUN2011}}$.

\section{Discussion}

Following the 2011 epidemic, key genetic, antigenic and phenotypic characteristics of $\mathrm{WNV}_{\mathrm{KUN} 2011}$ were investigated to ascertain why there was such a dramatic impact from what was considered to be a relatively attenuated strain of WNV [6]. In mouse virulence studies, $\mathrm{WNV}_{\text {KUN2011 }}$ was considerably more neuroinvasive than the prototype $\mathrm{WNV}_{\mathrm{KUN}}$ and $\mathrm{WNV}_{\mathrm{KUN} 2009}$ in both weanling and young adult mice ([6]; Prow et al. unpublished data).

The report by Frost et al. [6] suggested that the $\mathrm{WNV}_{\text {KUN2011 }}$ was more virulent and may be transmitted more efficiently between mosquitoes and mammalian 
hosts. In the current study, we assessed a number of attributes that constitute the vector competence of a mosquito species, including susceptibility to infection, virus replication dynamics and ability to transmit the virus. Although there was no significant difference in transmission rate of the two viruses by $C x$. annulirostris, more $\mathrm{WNV}_{\text {KUN2011 }}$ was expectorated than $\mathrm{WNV}_{\text {KUN2009 }}$ on days 1014 post-exposure and significantly more on days 12 and 14. Given the high titers of virus that mosquitoes were exposed to in the transmission experiments, we believe that the $10^{0.5} \mathrm{TCID}_{50} / \mathrm{mL}$ difference in titer between the $\mathrm{WNV}_{\mathrm{KUN} 2011}$ and $\mathrm{WNV}_{\mathrm{KUN} 2009}$ blood meals would have had a negligible impact on the outcomes of this study.

An increased amount of virus expectorated by mosquitoes may lead to hosts being inoculated with a higher dose of virus than would occur with other $\mathrm{WNV}_{\mathrm{KUN}}$ strains. However, we are unaware of any study that provides the precise dose of virus expectorated by a mosquito that is required to infect a vertebrate host or cause clinical disease in a host. Therefore, needle inoculation is often used as a proxy for mosquito infection and to standardize the dose of virus inoculated into a host. Using this mode of infection, it has been shown that higher doses lead to earlier and more enhanced WNV viremia levels [25,26] and increased oral shedding [27] in birds than lower doses. Thus, it is plausible that during the 2011 epidemic, infection of ardeid birds by higher doses of $\mathrm{WNV}_{\mathrm{KUN2011}}$ may have led to a more rapid onset of an elevated viremia, which, in turn, led to the infection of a greater proportion of mosquitoes, a higher rate of virus replication and increased transmission. Furthermore, higher amounts of virus expectorated by mosquitoes may have led to a greater proportion of horses being inoculated with a dose of virus capable of inducing clinical disease. A dose response to infection has been demonstrated with a number of WNV strains in mouse models, with higher doses leading to more rapid onset of disease and higher mortality [28,29].

In addition to increased transmissibility of $\mathrm{WNV}_{\mathrm{KUN} 2011}$ by mosquitoes, other intrinsic and extrinsic factors likely influence the role of $C x$. annulirostris in transmission cycles. Some of these factors are important parameters that are used to assess the vectorial capacity of a given species for an arbovirus and include daily survival rate, extrinsic incubation period (EIP) of the virus, population density, and host feeding behaviour [30]. Because an infected mosquito must survive the EIP for transmission to occur, mosquito survival is one of the key components of vectorial capacity. Field studies estimate the daily survival rate of $C x$. annulirostris to be $70-85 \%$, so it has been estimated that $<20 \%$ of the population survive the 810 day EIP to transmit MVEV, another important encephalitic flavivirus in Australia [31-33]. Considering that it was at days 12 and 14 post-exposure when we significantly higher amounts of $\mathrm{WNV}_{\mathrm{KUN} 2011}$ being expectorated, it is likely that only a very small proportion of the $C x$. annulirostris population would survive to transmit at these time points in the field, potentially offsetting the field impact of our laboratory observation.

The significantly higher than average rainfall experienced during 2010 and 2011 produced widespread freshwater larval habitats suitable for $C x$. annulirostris. Thus, it was not surprising that there was an explosive increase in density of this species, with $C x$. annulirostris dominant in trap collections that yielded over 10,000 mosquitoes per trap [12]. Widespread flooding would also have provided an ideal habitat for ardeid birds [4]. Analysis of host feeding patterns has previously identified $C x$. annulirostris blood meals from the Rufous Night Heron, Nycticorax caledonicus [34], so the convergence between high populations of amplifying hosts and vectors may have contributed to the widespread nature of the outbreak. Given that $C x$. annulirostris is an opportunistic blood feeder [34], this species may have not only acted as an epizootic vector cycling the virus between birds, but may have served as a bridge vector transmitting the virus to susceptible horses.

In our experiments, $C x$. australicus did not have increased vector competence for $\mathrm{WNV}_{\mathrm{KUN2011}}$ compared to $\mathrm{WNV}_{\mathrm{KUN} 2009}$ and had a significantly lower transmission rate for both virus strains than $C x$. annulirostris. Although no isolates of $\mathrm{WNV}_{\mathrm{KUN} 2011}$ were obtained from Cx. australicus during the 2011 outbreak, this species has yielded $\mathrm{WNV}_{\mathrm{KUN}}$ isolates previously [35]. Despite this, given that $C x$. australicus feeds predominately on birds [36,37] it may have played a role in epizootic amplification of the virus, especially where populations were higher than average. The substantial role of poorly competent vectors in arbovirus transmission cycles has been demonstrated previously, with biological traits, such as specific host feeding patterns or high population densities negating relatively low transmission rates [38,39].

Although the primary objective of the current study was to characterize $\mathrm{WNV}_{\mathrm{KUN2011}}$ in Cx. annulirostris, it is possible that other mosquito species may have contributed to the 2011 epidemic. Another member of the Cx. pipiens group, Culex quinquefasciatus is a highly efficient vector of $\mathrm{WNV}_{\mathrm{NY} 99}$ [40], exhibits ornithophilic host feeding patterns [34] and was abundant at some sites during the $\mathrm{WNV}_{\mathrm{KUN2011}}$ outbreak [12]. While there is no data on local vector competence of Culex molestus, this species, as part of the Cx.pipiens group globally, is widely distributed within the region of $\mathrm{WNV}_{\mathrm{KUN}}$ activity [41] and based on international studies, should be considered a potential vector [42]. Finally, floodwater Aedes, such as Aedes theobaldi, Aedes vittiger, Aedes eidsvoldensis and Aedes sagax were also abundant during the 
20102011 season [12] and may have played a role in transmission. Clearly, further studies are required to elucidate the role of other mosquito species in transmission of WNV $\mathrm{KUN2011}_{\text {and }}$ related flaviviruses.

The 2011 outbreak of equine encephalitis attributed to infection with $\mathrm{WNV}_{\mathrm{KUN2011}}$ was unprecedented. It was geographically widespread and $\mathrm{WNV}_{\mathrm{KUN}}$ activity appeared for the first time near populous centers of the east coast. Above average rainfall again triggered high mosquito population densities in some inland locations during the 20112012 season [43]. However, it did not result in continued widespread virus activity and very few cases of neurological disease in horses have been reported since 20102011 [44]. A $2012 \mathrm{WNV}_{\mathrm{KUN}}$ isolate showed similar levels of virulence asWNV $\mathrm{KUN2011}_{\text {in }}$ mice (Prow et al. unpublished data), suggesting continued circulation of this pathogenic strain.

\section{Conclusions}

To assess the relative fitness of $\mathrm{WNV}_{\mathrm{KUN} 2011}$ in $C x$. annulirostris, we examined susceptibility of this species to infection, replication dynamics and ability to transmit the virus. One of the key findings of the study was more efficient transmission of this virus strain at the later days post infection, when compared to the less pathogenic $\mathrm{WNV}_{\mathrm{KUNV}} \mathrm{No09}$ strain. Because WNV transmission cycles involve a complex interaction between the virus, vertebrate host and mosquito vector [1], results from laboratory-based experiments should not be viewed in isolation but need to be placed into an ecological context. Therefore it is more likely that a combination of more efficient transmission of $\mathrm{WNV}_{\mathrm{KUN2011}}$ by $C x$. annulirostris, elevated mosquito populations, an abundance of ardeid birds serving as amplifying hosts, opportunistic blood feeding habits of the key vector and increased pathogenicity of the virus in horses may have driven the 2011 equine epidemic in southeastern Australia.

\section{Competing interests}

The authors declare that they have no competing interests.

\section{Authors contributions}

AFvdH, SH-M, CEW and RAH conceived and designed the experiments; AFvdH, SH-M and CEW conducted the experiments; SH-M, CSET and NAP analysed the samples; AFvdH and FDF performed the statistical analysis; and AFvdH, SH-M, CEW, FDF, NAP and RAH prepared the manuscript. All authors read and approved the final version of the manuscript.

\section{Acknowledgements}

We thank Peter Kirkland and Cheryl Johansen for providing the New South Wales and Western Australia virus isolates. We acknowledge Stephen Doggett and John Haniotis for assistance with mosquito collection and blood feeding. We thank Cassie Jansen for comments on a draft of the manuscript. This study was funded by an Australian Research Council Linkage Grant (Project ID:LP120100686).

\section{Author details}

${ }^{1}$ Virology, Public and Environmental Health, Forensic and Scientific Services, Department of Health, Queensland Government, Brisbane, QLD, Australia.
${ }^{2}$ Australian Infectious Disease Research Centre, School of Chemistry and Molecular Biosciences, University of Queensland, Brisbane, QLD, Australia. ${ }^{3}$ Department of Medical Entomology, University of Sydney and Pathology West ICPMR Westmead, Westmead, NSW, Australia. ${ }^{4}$ Institute of Health and Biomedical Innovation and School of Biomedical Sciences, Queensland University of Technology, Kelvin Grove, QLD, Australia.

Received: 21 August 2014 Accepted: 2 December 2014

Published online: 12 December 2014

\section{References}

1. Kramer LD, Styer LM, Ebel GD: A global perspective on the epidemiology of West Nile virus. Ann Rev Entomol 2008, 53:61 81.

2. Petersen LR, Brault AC, Nasci RS: West Nile virus: review of the literature. JAMA 2013, 310:308 315.

3. Hall RA, Broom AK, Smith DW, Mackenzie JS: The ecology and epidemiology of Kunjin virus. Curr Top Microbiol Immunol 2002, 267:253 269.

4. Marshall ID: Murray Valley and Kunjin Encephalitis. In The Arboviruses: Epidemiology and Ecology. Vol. 3. Edited by Monath TP. Boca Raton, Florida: CRC Press; 1988:151 189.

5. Roche SE, Wicks R, Garner MG, East IJ, Paskin R, Moloney BJ, Carr M, Kirkland $P$ : Descriptive overview of the 2011 epidemic of arboviral disease in horses in Australia. Aust Vet J 2013, 91:5 13

6. Frost MJ, Zhang J, Edmonds JH, Prow NA, Gu X, Davis R, Hornitzky C, Arzey KE, Finlaison D, Hick P, Read A, Hobson-Peters J, May FJ, Doggett SL, Haniotis J, Russell RC, Hall RA, Khromykh AA, Kirkland PD: Characterization of virulent West Nile virus Kunjin strain, Australia, 2011. Emerg Infect Dis 2012, 18:792 800.

7. Ostlund EN, Crom RL, Pedersen DD, Johnson DJ, Williams WO, Schmitt BJ: Equine West Nile encephalitis, United States. Emerg Infect Dis 2001, 7:665 669.

8. Williams SA, Richards JS, Faddy HM, Leydon J, Moran R, Nicholson S, Perry F, Paskin R, Catton M, Lester R, Mackenzie JS: Low seroprevalence of Murray Valley encephalitis and Kunjin viruses in an opportunistic serosurvey, Victoria 2011. Aust N Z J Public Health 2013, 37:427 433.

9. Komar N, Langevin S, Hinten S, Nemeth N, Edwards E, Hettler D, Davis B, Bowen R, Bunning M: Experimental infection of North American birds with the New York 1999 strain of West Nile virus. Emerg Infect Dis 2003, 9:311 322.

10. Steele KE, Linn MJ, Shoepp RJ, Komar N, Geisbert TW, Manduca RM, Calle PP, Raphael BL, Clippinger TL, Larsen T, Smith J, Lanciotti RS, Panella NA, McNamara TS: Pathology of fatal West Nile virus infections in native and exotic birds during the 1999 outbreak in New York City, New York. Vet Path 2000, 37:208 224.

11. Bureau of Meteorology: Record-Breaking La Nia Events. Melbourne, Australia: Bureau of Meteorology; 2012.

12. Doggett S, Clancy J, Haniotis J, Webb C, Russell RC, Hueston L, Dwyer DE: The New South Wales Arbovirus Surveillance and Mosquito Monitoring Program 20102011 Annual Report. Westmead, Australia: Department of Medical Entomology, ICPMR, Westmead Hospital; 2011.

13. Ebel GD, Carricaburu J, Young D, Bernard KA, Kramer LD: Genetic and phenotypic variation of West Nile virus in New York, 20002003. Am J Trop Med Hyg 2004, 71:493 500.

14. Moudy RM, Meola MA, Morin LL, Ebel GD, Kramer LD: A newly emergent genotype of west nile virus is transmitted earlier and more efficiently by Culex mosquitoes. Am J Trop Med Hyg 2007, 77:365 370.

15. Savage HM, Ceianu C, Nicolescu G, Karabatsos N, Lanciotti R, Vladimirescu A, Laiv L, Ungureanu A, Romanca C, Tsai TF: Entomologic and avian investigations of an epidemic of West Nile fever in Romania in 1996, with serologic and molecular characterization of a virus isolate from mosquitoes. Am J Trop Med Hyg 1999, 61:600 611.

16. Turell MJ, Dohm DJ, Sardelis MR, Oguinn ML, Andreadis TG, Blow JA: An update on the potential of North American mosquitoes (Diptera: Culicidae) to transmit West Nile virus. J Med Entomol 2005, 42:57 62.

17. Russell RC: A review of the status and significance of the species within the Culex pipiens group in Australia. J Am Mosa Control Assoc 2012, 28:24 27.

18. Rohe D, Fall RP: A miniature battery powered $\mathrm{CO}_{2}$ baited light trap for mosquito borne encephalitis surveillance. Bull Soc Vector Ecol 1979, 4:24 27. 
19. Goddard LB, Roth AE, Reisen WK, Scott TW: Vector competence of California mosquitoes for West Nile virus. Emerg Infect Dis 2002, 8:1385 1391.

20. Aitken THG: An in vitro feeding technique for artificially demonstrating virus transmission by mosquitoes. Mosq News 1977, 37:130 133.

21. Turell MJ, Gargan TP II, Bailey CL: Replication and dissemination of Rift Valley fever virus in Culex pipiens. Am J Trop Med Hyg 1984, 33:176 181.

22. Broom AK, Hall RA, Johansen CA, Oliveira N, Howard MA, Lindsay MD, Kay $\mathrm{BH}$, Mackenzie JS: Identification of Australian arboviruses in inoculated cell cultures using monoclonal antibodies in ELISA. Pathology 1998, 30:286 288

23. Reed $L$, Meunch $H$ : A simple method for estimating fifty percent end points. Am J Hyg 1938, 27:493 497.

24. GraphPad Software: GraphPad Prism. Version 6. San Diego, CA: GraphPad Software, Inc; 2012.

25. Reisen WK, Fang Y, Martinez VM: Avian host and mosquito (Diptera: Culicidae) vector competence determine the efficiency of West Nile and St. Louis encephalitis virus transmission. J Med Entomol 2005, 42:367 375.

26. Styer LM, Bernard KA, Kramer LD: Enhanced early West Nile virus infection in young chickens infected by mosquito bite: effect of viral dose. Am J Trop Med Hyg 2006, 75:337 345.

27. VanDalen KK, Hall JS, Clark L, McLean RG, Smeraski C: West Nile virus infection in American Robins: new insights on dose response. PLoS One 2013, 8:e68537.

28. Prow NA, Setoh YX, Biron RM, Sester DP, Kim KS, Hobson-Peters J, Hall RA, Bielefeldt-Ohmann $\mathrm{H}$ : The West Nile-like flavivirus Koutango is highly virulent in mice due to delayed viral clearance and the induction of a poor neutralizing antibody response. J Virol 2014, 88:9947 9962.

29. Audsley M, Edmonds J, Liu W, Mokhonov V, Mokhonova E, Melian EB, Prow N, Hall RA, Khromykh AA: Virulence determinants between New York 99 and Kunjin strains of West Nile virus. Virology 2011, 414:63 73

30. Kramer LD, Ebel GD: Dynamics of flavivirus infection in mosquitoes. Adv Virus Res 2003, 60:187 232.

31. Kay BH: Age structure of populations of Culex annulirostris (Diptera: Culicidae) at Kowanyama and Charleville, Queensland. J Med Entomol 1979, 16:309 316.

32. Russell RC: Population age composition and female longevity of the arbovirus vector Culex annulirostris Skuse near Echuca, Victoria, in the Murray Valley of southeastern Australia 1979 1985. Aust J Exp Biol Med Sci 1986, 64:595 606.

33. Kay BH: Towards prediction and surveillance of Murray Valley encephalitis activity in Australia. Aust J Exp Biol Med Sci 1980, 58:67 76

34. Jansen CC, Webb CE, Graham GC, Craig SB, Zborowski P, Ritchie SA, Russell $\mathrm{RC}$, van den Hurk AF: Blood sources of mosquitoes collected from urban and peri-urban environments in eastern Australia with species-specific molecular analysis of avian blood meals. Am J Trop Med Hyg 2009, 81:849 857.

35. Marshall ID: Epidemiology of Murray Valley encephalitis in eastern Australia patterns of arbovirus activity and strategies of arbovirus survival. Arbovirus Res Aust 1979, 2:47 53.

36. Kay BH, Boreham PFL, Fanning ID: Host-feeding patterns of Culex annulirostris and other mosquitoes (Diptera: Culicidae) at Charleville, southwestern Queensland, Australia. J Med Entomol 1985, 22:529 535.

37. Kay BH, Boyd AM, Ryan PA, Hall RA: Mosquito feeding patterns and natural infection of vertebrates with Ross river and Barmah Forest viruses in Brisbane, Australia. Am J Trop Med Hyg 2007, 76:417 423.

38. Miller BR, Monath TP, Tabachnick WJ, Ezike VI: Epidemic yellow fever caused by an incompetent mosquito vector. Trop Med Parasitol 1989, 40:396 399

39. Turell MJ, O Guinn ML, Dohm DJ, Jones JW: Vector competence of North American mosquitoes (Diptera: Culicidae) for West Nile virus. J Med Entomol 2001, 38:130 134

40. Jansen CC, Webb CE, Northill JA, Ritchie SA, Russell RC, van den Hurk AF: Vector competence of Australian mosquito species for a North American strain of West Nile virus. Vector Borne Zoonotic Dis 2008, 8:805 811.

41. Kassim NFA, Webb CE, Wang QN, Russell RC: Australian distribution, genetic status and seasonal abundance of the exotic mosquito Culex molestus (Forskal) (Diptera: Culicidae). Aust J Entomol 2013, 52:185 198.

42. Jansen CC, Ritchie SA, van den Hurk AF: The role of Australian mosquito species in the transmission of endemic and exotic West Nile virus strains. Int J Environ Res Public Health 2013, 10:3735 3752
43. Doggett S, Clancy J, Haniotis J, Webb C, Russell RC, Hueston L, Dwyer DE: The New South Wales Arbovirus Surveillance and Mosquito Monitoring Program 20112012 Annual Report. Westmead, Australia: Department of Medical Entomology, ICPMR, Westmead Hospital; 2012.

44. Prow NA: The changing epidemiology of Kunjin virus in Australia. Int $J$ Environ Res Public Health 2013, 10:6255 6272.

doi:10.1186/s13071-014-0586-3

Cite this article as: van den Hurk et al:: Role of enhanced vector transmission of a new West Nile virus strain in an outbreak of equine disease in Australia in 2011. Parasites \& Vectors 2014 7:586.

\section{Submit your next manuscript to BioMed Central and take full advantage of:}

هConvenient online submission

$\otimes$ Thorough peer review

$\nabla$ No space constraints or color $\nabla$ gure charges

$\otimes I m m e d i a t e$ publication on acceptance

\Inclusion in PubMed, CAS, Scopus and Google Scholar

$\otimes$ Research which is freely available for redistribution

Submit your manuscript at www.biomedcentral.com/submit
C) Biomed Central 